\title{
ARTERIAL COMPLIANCE IN HYPERTENSION
}

\author{
Otelio S. Randall, Murray D. Esler, Richard V. Calfee,
}

Gerald F. Bulloch, Alan S. Maisel and Brenda Culp

The Department of Internal Medicine Hypertension and Cardiology Divisions University of Michigan Medical Center, Ann Arbor, Michigan 48109 USA

Study of the viscoelastic properties of the arterial tree in man is difficult. Most previous reports on arterial compliance (distensibility) in man, in which compliance has been estimated directly from pressure-volume relationships, have involved arteries taken from cadavers, $(1,2)$. In vivo studies in humans have usually utilized indirect estimates of campliance (3-8), such as arterial pulse wave velocity $(5,8)$.

Arterial compliance has been a somewhat neglected subject in recent cardiovascular research; this probably reflects methodological difficulties rather than lack of interest (3-7) and does not imply that aberrations in arterial distensibility play no important role in human circulatory pathophysiology and disease. Loss of arterial compliance is seen as part of the process of arterial aging $(1-4,6,9-11)$. In vitro studies have documented a diminution in compliance in arterial hypertension in man $(1,2)$. Reduced arterial compliance in man has been related to systolic hypertension in the elderly $(3,11)$ and to abnormal baroreflex function in hypertensive subjects $(5,12)$.

A method for studying arterial compliance in vivo in man would be of considerable value. We have developed a technique for estimating arterial compliance from the intra-arterial pressure pulse contour and calculated total peripheral vasomotor resistance (13). The method is based on the relationship of the change in arterial volume $(\Delta V)$ during a selected interval of the diastolic runoff period, to the fall in pressure ( $\triangle P$ ) that this change in volume produces. Since this method is a direct expression of pressurevolume relationships, it carries potential advantages over other indirect estimates of. arterial compliance, such क those based on

Correspondence to:

Otelio S. Randall, M.D.

R 6669 Kresge Medical Research Building

University of Michigan Medical Center

Ann Arbor, Michigan 48109 USA pulse wave velocity measurements $(5,8)$.

METHODS AND MATERIALS

Patient Groups:

Arterial compliance was estimated in 27 subjects undergoing diagnostic cardiac catheterization who had no evidence of aortic valvular disease or of intra- or extracardiac shunts. Three groups were defined: Group I, eight normotensive patients (intra-arterial blood pressure less than $140 \mathrm{~mm} \mathrm{Hg}$ systolic and $90 \mathrm{~mm} \mathrm{Hg}$ diastolic) (5 men (m) $/ 3$ wamen (w) under the age of 40 ; Group II, 13 normotensive patients $(9 \mathrm{~m} / 4 \mathrm{w})$ over the age of $40 ;$ Group ITI, six hypertensive patients $(5 \mathrm{~m} / \mathrm{l} \mathrm{w})$ under the age of 40 . All hypertensive patients met at least two of the three following criteria: brachial intraarterial blood pressure >140 mm Hg systolic, $>90 \mathrm{~mm} \mathrm{Hg}$ diastolic, or $\geq 100 \mathrm{~mm}$ $\mathrm{Hg}$ mean.

Catheterization Procedure and Measurement of Haemodynamic Variables:

None of the hypertensives had received sympatholytical drugs. A number 6 or $7 \mathrm{~F}$ Eppendorf $\mathrm{R}_{\text {catheter was }}$ passed to the pulmonary artery through a venotany. A polyethylene catheter was placed in the brachial artery and the dead space of the sampling system and the rate of withdrawal was taken into account. Indocyamine green, $2.5 \mathrm{mg}$ was injected rapidly into the pulmonary artery, employing a saline flush. Three calibration points were used for the densitometer and cardiac output was calculated by the method of Hamilton et al (14).

A number 6,7 or $8 \mathrm{~F}$ Eppendorf $R$ catheter was then placed in the brachial artery and advanced to the ascending aorta where pressure-pulse contour was again recorded at $200 \mathrm{~mm} / \mathrm{sec}$. on a calibrated $E$ for $M$ recorder. The estimation of arterial compliance was based on measurements from 2-6 arterial pressurepulse contours at each site. 
Estimation of Arterial Compliance Index:

Windkessel theory $v$ iews the (central) arterial system as an elastic chamber with a linear pressure-volume relationship between end-systole and enddiastole $(7,15)$. However, arterial compliance which is measured as the change in volume that accomparies a unit change in pressure $(\mathrm{LV} / \mathrm{LP})$ is nonlinear $(1,2)$ and describes the physical properties (viscoelastic) of the walls of the large and modium arteries. The present approach to measurement of systemic arterial compliance depends on the simultaneous estimation of change in arterial volume and arterial pressure during diastolic runoff.

For the estimation of change in arterial volume (AV), that is flow out of the arterial system into the capillary bed, of necessity an indirect method is used. The estimation of $\Delta V$ is based on the relationship between the instantaneous rate of change in arterial volume, dv/dt, during diastolic runoff, and the instantaneous arterial pressure $(P)$. If two simplifying assumptions are made, first of a linear relation of flow to pressure at pressures above approximately $20 \mathrm{~mm} \mathrm{Hg} \mathrm{(16,}$ 17) and second that the pressures used during diastolic runoff are the same throughout the oentral arterial systom, the change in arterial volume for the period $t_{1}-t_{2}$ (Fig. 1), may be calculated. This is accomplished by integrating to find the area under a designated portion of the arterial pressure pulse curve in diastole (eliminating the area of assumed physiological nonlinearity for the relationship of flow to pressure, that is below $20 \mathrm{~mm} \mathrm{Hg}$ ), and dividing by the resistance to flow from the central arterial system (total vascmotor resistance). The portion of the diastolic pressure pulse contour used, from $t_{1}$ (0.06-0.08 sec after the peak of the aicrotic wave) to $t_{2}(0.20-0.24 \mathrm{sec}$ after $t_{1}$ ) was chosen to avoid aberrations known to occur in the brachial pressure pulse contour, when compared with the aortic pressure pulse contour during systole and the dicrotic wave (18). The corresponding change in pressure is measured directly fram the pressure pulse contour.

Change in volume $(\Delta V)$ is adjusted for body surface area (BSA) to correct for differences in body size, and $A C I$, the mean arterial compliance index ( $\triangle \mathrm{V} / \mathrm{BSA} / \mathrm{P}$ ) calculated. (See Appendix).

\section{RESTJITS}

The general characteristics and haenodynamic measurements of the 27 patients studied are shown in Table 1 .

Arterial compliance index decreased with age. Thene was a simnificant inverse correlation between age and ACI. in normotensive subjects; $r=-0.496$, p 0.05 (Fig. 2). There was also an inverse relationship between arterial compliance index and blood pressure (Fig. 3). Further, in an individual subject, ACI was dependent upon instantaneous blood pressure. With spontaneous changes in blood pressure, ACI varied in a systematic, inverse fashion with blood pressure (Fig. 3) . Consequently, the ease with which the systemic arterial system could be distended (ACI) increased as blood pressure fell.

The relationship of ACI to blood pressure and to age was further evaluated by comparing ACI in two patient groups, matched in one instance for age, and in the other for blood pressure. ACI was compared in the nomotensive groups I and II, matched for blood pressure (mean blood pressure $81 \pm 5 \mathrm{~mm}$ and $82 \pm 8 \mathrm{~mm}$ ) but with a significant aifference in age $(32.0$ \pm 6.4 yrs. and $53.4 \pm 8.8$ yrs, $\mathrm{p}<0.01$ )* The significantly lower ACI in the older patients $\left(0.678 \pm 0.191 \mathrm{ml} / \mathrm{mm} \mathrm{Hg} . \mathrm{m}^{2}\right.$ and $0.975 \pm 0.191 \mathrm{ml} / \mathrm{mm} \mathrm{Hg} \cdot \mathrm{m}^{2}, \mathrm{p}<0.01$ ) is attributed to the effect of age on the arterial system and not to any minor differences in arterial blood pressure that may have existed. Patients of similar ago $(32.0 \pm 6.4$ yrs and $31.0 \pm 6.1$ yrs $)$, but with a significant difference in blood pressure (Group I vs Group III) (mean blood pressure $81 \pm 5 \mathrm{~mm}$ and $106 \pm 11 \mathrm{~mm}, \mathrm{p}<0.01)$ were also compared. The ACI was significantly lower in the hypertensive group $10.577 \pm 0.170$ and $0.975 \pm 0.191 \mathrm{mI} / \mathrm{mm}$ $\left.\mathrm{Hg} . \mathrm{m}^{2}, \mathrm{p}<0.0 \mathrm{I}\right)$

Thus, blood pressure and age appear to act as independent determinants of arterial compliance. When the ACI was compared in the older nomotensive subjects (Group II) and the young hypertensives (Group III), no significant

* The significance levels of the difference between groups were determined by Scheffé multiple comparison confidence levels. (Scheffé, $\mathrm{H}$ : Analysis of Variance, New York, John Wiley \& Sons, Inc. 1959, PP 66-72) 


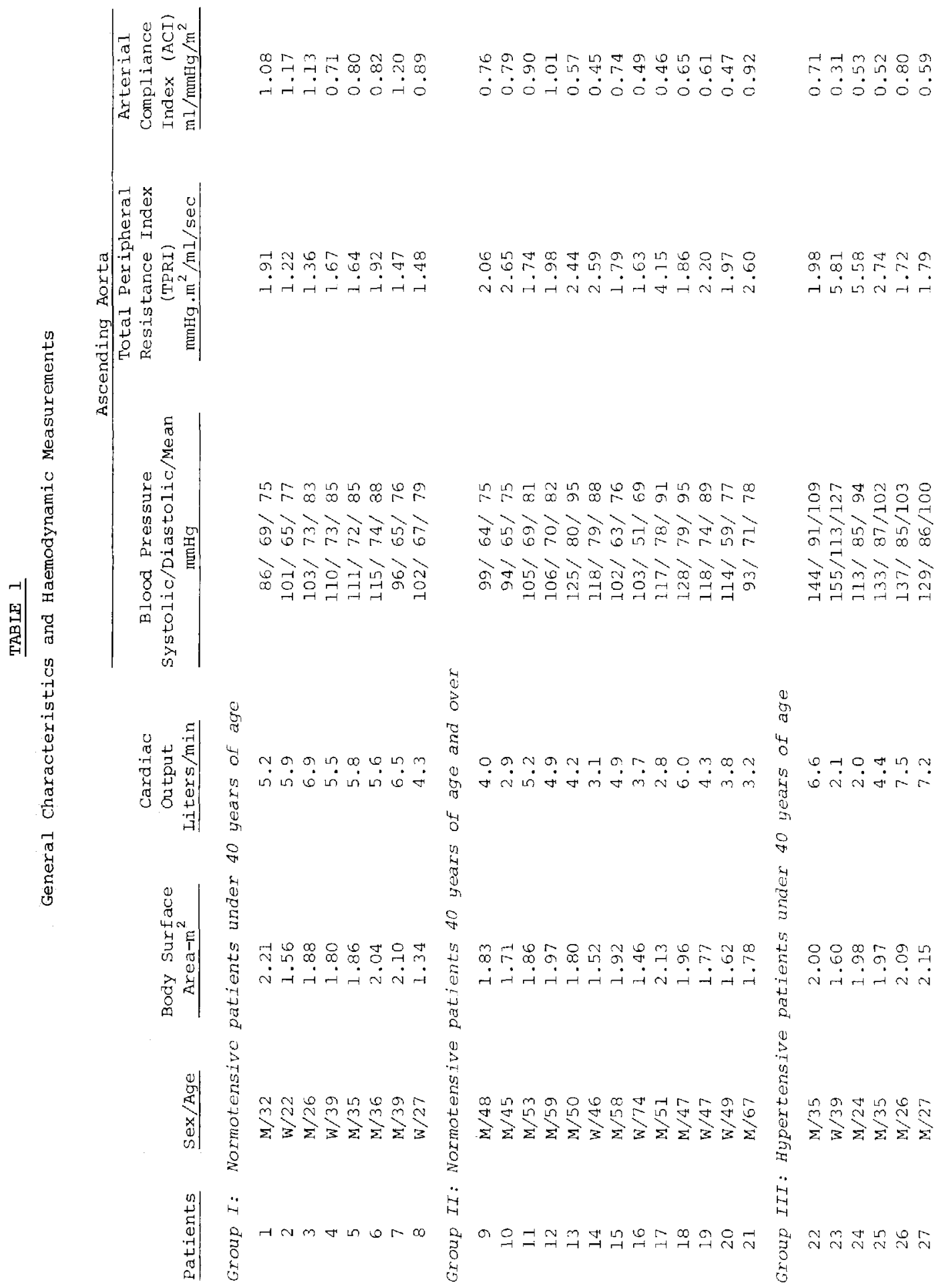


difference was noted $(0.678 \pm 0.191$ and $0.577 \pm 0.170 \mathrm{ml} / \mathrm{mm} \mathrm{Hg.m} 2, \mathrm{n.5.})$. Data obtained from the brachial artery site were similar to those shown for the aorta.

Since calculations of ACI involve total peripheral vascmotor resistance, $\mathrm{R}_{\mathrm{V}}$ (equation 10, appendix) the contribution of $\mathrm{R}_{\mathrm{v}}$ to the correlation of ACI with systolic blood pressure was evaluated. The correlation coefficient of ACI with systolic blood pressure was $r=-0.754, p<0.01$. When the contribution of $k_{V}$ to this correlation was removed by partial correlative analysis, the correlation was similar, $r=-0.626, p<0.01$. This finding supports the observed decrease in ACI with increasing blood pressure (Fig. 3) as being real and not a spurious mathenatical relationship dependent on any contribution of $R_{V}$ to blood pressure.

Th test the reliability of the estimates of systemic arterial compliance derived from pressure-pulse contours recorded in a peripheral artery, measurements were made at two arterial sites: one peripheral, the brachial, and one central, the ascending aorta, in 33 subjects ( 6 of wham did not meet the criteria for Groups I-III, Table 1). Measurements were made consecutively in the brachial artery and the aorta at approximately 30 -second intervals. Mean arterial compliance indices derived from pressure-pulse contours at the two sites were similar, and the within-patient correlation coefficients for arterial compliance index derived from measurements at the two arterial sites approached unity (Fig. 4).

\section{DISCUSSION}

Aterial compliance, like total peripheral resistance, is an important part of total systemic arterial impedance $(19,20)$. The measurement of arterial compliance in cardiovascular diseases, however, has received less attention than peripheral resistance, probably as a consequence of the lack of an available technique for directly measuring compliance in man, rather than any lack of interest. The index of arterial campliance usod most commonly is an indirect one, not based directly on arterial pressure-volume relationships, namely arterial volume distensibility calculated from the arterial pulse wave (conduction) velocity $(5,8)$. Most previous reports of arterial compliance measurements in man of necessity have been in vitro studies on arteries removed from cadavers $(1,2)$.

In the present method arterial compliance was calculated from arterial pressure-pulse contours and haemodynamic measurements. The estimation of compliance is based on the relationship of the change in systemic arterial volume during a selected interval of the diastolic runoff period, to the fall in pressure that this change in volume produces. Since this method is a direct expression of arterial pressure-volume relationships, it carries potential advantages over indirect estimates of arterial compliance, such as those based on pulse wave velocity measurements $(5,8)$. It should be emphasised that what is calculated here is an overall compliance figure, representing a weighted mean of the differing compliances, of the systemic arteries in different parts of the arterial system.

In the present study, an effect of blood pressure and of age on systemic arterial compliance was demonstrated. This finding is in agreement with previous in vitro studies $(1,2)$. Concordance with the findings of these studies, in which arterial campliance was measured directly in vitro, provides support for the usefulness of the present method for in vivo evaluation of systemic arterial compliance in man. However, it should be stressed that the accuracy of the method presented here for the estimation of overall systemic arterial omplianoe is dependent on the acceptability of two assumptions made to facilitate the calculation of change in arterial volume. First, that resistance to flow out of the central arterial system, vasomotor resistance (13), is constant above a pressure of $20 \mathrm{~mm} \mathrm{Hg}(16,17)$ and second, that the pressures used during diastolic nunoff are the same throughout the central arterial system. The assumption of a linear pressure-flow relationship seems reasonable since this is the same assumption used in the routine calculation of total peripheral resistance. The second part of assumption one, that of zero flow below $20 \mathrm{~mm} \mathrm{Hg}$, is perhaps more contentious The work of whittaker and winton (16) and Girling (17) appears to demonstrate an approximately linear relation of flow to pressure in manmalian systens, except at very low perfusing pressures, such as below $20 \mathrm{~mm} \mathrm{Hg}$. However, there is same dispute on this question of the linearity of the pressure-flow relationship. Green 
et al. described the variation of flow with pressure as being an approximately exponential rather than inear function (21). We have adopted the most generally held view, that of a linear pressire-flow relationship above $20 \mathrm{~mm} \mathrm{Hg}$, in computing $\Delta V$ from the arterial pressure-pulse contours. The $20 \mathrm{~mm} \mathrm{Hg}$ value is somewhat arbitrary, but approximates the pressuro at wich flow is zero $(16,17)$ and has been used most often by workers in this area $(22,23,24)$.

In the present study systemic arterial complianoe proved to be related to the level of the blood pressure. This relationship was of two types: a reduction in compliance in patients with essential hypertension, and spontaneous changes in compliance with respect to variation in blood pressure. This change in arterial compliance with spontaneous changes in blood pressure presumably reflects the nonlinear viscoelastic behaviour of arterial walls as they are distended. With small spontaneous rises in blood pressure, in the somewhat more distended arterial tree, the compliance was lowei; conversely, with small. decreases in pressure, compliance rose.

In the hypertensive patients, arterial compliance index was clearly below normal. The presence of diminished systemic arterial compliance in hypertension could be an expression of this phenomenon of reduced distensibility of the arterial tree at higher distending pressures and larger arterial volumes. An additional mechanism, however, may be operating. In established hypertension structural changes develop in the arterial wall. $(1,11)$. The subnormal compliance index in hypertension may be partly a consequence of these structural changes.

Diminished arterial campliance in hypertension may possibly have important pathophysiological consequences. One example may be the subnomal arterial baroreflex sensitivity noted in essential hypertension (25-27). This may well be secondary to reduced distensibility of the arterial wall at the site of the carotid and aortic arterial baroreceptors. Such a relationship between decreased arterial compliance index in essential hypertension and reduced baroreflex sensitivity has recently been reported (12). compliance with aging has been reported here and by others $(1,2,6)$. As in hypertension, this loss of arterial distensibility with age probably is partly based on structural changes in the arterial wall $(1,11)$. This reduction of arterial compliance with age may well have pathophysiological consequences. Systolic hypertension in the eldorly is widely regardod to be an expression of reduced arterial compliance secondary to atherosclemsis and also nonatherosclerotic aqing of the arterial wall $(3,1.1)$.

\section{of importance, in terms of}

the possible clinical utilization of measurement of arterial compliance, is the finding that estimates of arterial compliance, as derived from the pressurepulse contour of a peripheral artery such as the brachial in the antecubital area, agree closely with values obtained with the catheter tip in the asconding aorta. The relative simplicity of percutaneous brachial artery puncture would support the brachial artery as the site of choice for determining arterial complianoe if this measure is found to be clinically useful. Differences between central and peripheral wave forns were noted, but these involved on $y^{y}$ the dicrotic wave and systolic portion of the pressurepulse ontour. This finding has also been reported by O'Rourke (18). Since we calculated arterial compliance from the diastolic portion of the curve, distal to the dicrotic wave, interference from such factors as reflected waves had no appreciable effect on this portion of the aortic and brachial pressure-pulse contour.

We have developed a method of estimating overall arterial compliance, this representing a weighted mean of the differeing compliances in the arteries throughout the arterial system. As such, the measurement is a value of physiological significance because it is a measure of one component of the irnpedance against which the left ventricle must work $(19,20)$. Although arterial compliance is a functionally important component of systemic arterial impedance, its systematic study in human disease has been somewhat neglected because of lack of suitable methods. It is hoped that the described technique for evaluating overall systemic arterial compliance index will prove useful in evaluating the overall status of the cardiovascular system. 


\section{APPENDTX}

The formal derivation of the equation for calculation of arterial compliance index $E_{O}(t)=\frac{I}{R_{V}}(P(t)-20)$

$$
\begin{aligned}
F_{O}(t) & =\text { flow out of arterial system (ml/sec) } \\
P(t) & =\text { pressure (mm } \mathrm{Hg}) \\
R_{\mathrm{V}} & =\text { total peripheral vasomotor resistance }(\mathrm{mm} \mathrm{Hg} / \mathrm{mI} / \mathrm{sec})
\end{aligned}
$$

To find the value of $R_{y}$ the data may be averaged over several cycles (time) $\left(0, T_{1}\right)$ :

$$
\frac{0^{T_{I_{F}}(t) d t}}{T_{1}}=\frac{1}{R_{V}} \frac{0^{f_{1}(P(t)-20) d t}}{T_{1}}=\frac{1}{R_{V}} \frac{0^{f^{T} I_{P}(t) d t}}{-\frac{20}{R_{V}}}
$$

However:

$$
\frac{\int^{T^{T}} I_{F}(t) d t}{T_{1}}=\text { average flow out of arterial system or cardiac output }(C O)
$$

And :

$$
\frac{\int^{T^{T} I_{P}(t) d t}}{T_{1}}=\text { average (mean) blood pressure (MBP) }
$$

Therefore:

Or:

$$
C O=\frac{I}{R_{V}}(M B P-20)
$$

$$
\mathrm{R}_{\mathrm{V}}=\frac{\mathrm{MBP}-20}{\mathrm{CO}}
$$

For any defined volume (in this case, the central arterial system) conservation of mass requires that the rate of change of the volume is equal to the sum of all flows into the volume $\left(F_{i}\right)$ less the sum of all flows out of the volume for incompressible fluid.

$\frac{d v(t)}{d t}=\sum F_{i}(t)-Z F_{0}(t)$

During diastole there is no flow into the system and therefore:

$\sum \mathrm{F}_{i}=0$

Also, for subjects with competent aortic valves and no extracardiac shunts the only flow out of the system is that flow to the capillary bed and therefore, from equations (1), (5) and (6):

$\frac{d V(t)}{d t}=-\frac{1}{R_{V}}(P(t)-20)$

Compliance is a measure of change in volume in the arterial system per unit change in pressure,

$C=\frac{\Delta V}{\Delta P}$

over any interval of time $t_{1}$ to $t_{2}$, during diastole we may calculate the change in volume in the central arterial system by integrating equation (7):

$\Delta v=t_{1}^{t_{2}} \frac{d v(t)}{d t} d t=-\frac{I}{R_{v}} t_{1}^{t_{2}}(p(t)-20) d t$ 
and therefore:

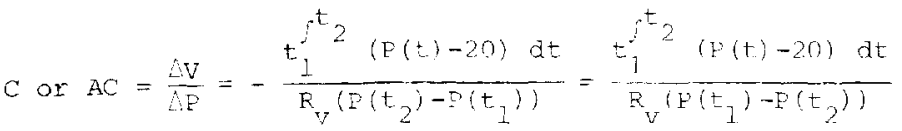

or:

$A C I=\frac{\frac{\Delta V}{\Delta P}}{B S A}=\frac{\Delta V}{\Delta P} \cdot \frac{I}{B S A}=\frac{A C}{B S A}$

The help of the following is gratefully acknowledqed: William Thomas, Jr., Mrs. Jane Bennett, Miss Judy Mertens, Mrs. Gail Tolles, Professor M. Anthony Schork. Robort J. Anderson, Professor Stevo Julius and Park Willis, I.I, M.D.

\section{REFFRENCES}

1. HALLOCK, P. and BENSON, I.C. (1937): studies on the elastic properties of human isolated aorta, J.Clin. Invest. , 15, 595 .

2. REMTNGTON, R.W., NOBACK, C.R., HAMTLTON, W.F. and GOID, J.J. (1948): Volume elasticity characteristics of the human aorta and prediction of the stroke volume from the pressure pulse, $\mathrm{Am}$. J. Physiol., 153, 298.

3. DUSTAN, H.P. (1974): Atherosclecosis complicating chronic hypertension, Circulation, 50, 871 .

4. DEFARES, J.G. and VAN DER WARL, II.J. (1969): A method for the determination of systemic arterial compliance in man, Acta Physiol. Neerl., 15, 329.

5. GRIBBIN, B., PICKERING, T.G. and SIEIGH, P. (1972-73): Arterial wall distensibility in hypertensive man (abstract), Q.J. Med.. 41-42, 531 .

6. ABBOUd, F.M. and HusTON, J.H. (1961): The effects of aging and degenerative vascular disease on the measurement of arterial riqiaity in man, J. Clin. Invest., 40, 933.

7. COPE, F.W. (1965): Elastic reservoir theories of the human circulation with applications to clinical medicine and to computer analysis of the circulation, in Advances in Biological and Medical Physics, Vol. 10, Iawrence, J.I. and Gofman, J.W. (ed.), Academic Press, New York, p. 277.

8. BRAMWELL, J.C. and HILL, A.V. (1922): The velocity of the pulse-wave in man, Froc. Foy. Soc., B93, 298.

9. BRAMWELL, J.C., HLLL, A.V. and MCSWINFY, B.A. (1923): The velocity of the pulse wave in man in relation to age as measured by the hot-wire sphygmograph, Heart, 10, 233 .

10. RANDAIL, O.S., CALFEE, R.V., ESLER, M.D. and BULLOCH, G.F. (1975): Evaluation of arterial compliance in man (abstract), Circulation, 52 (Suppl) $I I-228$.

11. CONWAY, J. and SMITH, K.S. (1957): Agjing of arteries in relation to hypertension, Circulation, 15, 827.

12. RANDAIL, O.S., ESIER, M.D., JUIIUS, S. and CALFEE, R.V. (1975): Assocjation of arterial compliance with baroreflex sensitivity in normotensive and hypertensive subjects (abstract), Clin. Res., 23, 203A.

13. HAMILTON, W.F. and REMTNGTON, J.W. (1948): Some factors in the regulation of the stroke volume, Am. J. Physiol., $153,287$.

14. HAMILION, W.F., RTLEY, R.L., ATTYYH, A.M., COURNAND, A., FOWELL, D.M., HIMMEISTEIN, A., NOBEL, R.P., REMINGTON J.W., RICIARDS, D.W., WIERIER, N.C. and WITHAM, A.C. (1948): Comparison of the Fick and dye injection methods of measuring the cardiac output in man, Am. J. Physiol., 153, 309.

15. FRANk, 0. (1899) : Die grundform des arteriellen pulses crste abhandlung: Mathematische analyse, Z. Biol. (Munich), 37,483 .

16. WHTTTAKER, S.R.F. and WINTON, F.R. (1933): The apparent viscosity of blood flowing in the isolated hindlimb of the dog and its variation with corpuscular concentration, J. Physiol., $78,339$. 
17. GIRLING, F. (1952): Vasomotor effects of electrical stimulation, An. J. Physial., 170, 131 .

18. O'ROURKE, M.F. (1970): Influence of ventricular ejection on the relationship between central aortic and brachial pressure pulse in man, Cardiovasc. Res., 4 4291.

19. BERNE, R.M. and LEVY, M.N. (1972): Cardiovascular Physiology, 2nd ed. The C.V. Mosby Company, st. Louis, p.84.

20. MILNOR, W.R. (1975) : Arterial jmpedarce as ventricular overload, Circ. Res., 36,565 .

21. GREEN, H.D., LEWIS, R.N., NICKERSON, N.D. and HELLER, A.L. (1944): Blood flow, peripheral resistance and vascular tonus, with observations on the relationship betweon blood Elow and cutaneous temperature, $\mathrm{Am}$. J. Physiol., 141, 518 .

22. HAMILTON, W.F, and REMINGTON, J.W. (1947): The measurement of the stroke volume from the pressure pulse, Am. J. Physiol.. 148, 14.

23. WARNER, H.R., SWAN, H.J.C., CONNOLLY, D.C., TOMPKINS, R.G. and WOOD, E.H. (1953): Quantjtation of beat-to-beat changes in stroke volume from the aortic pulse contour in man, J. Appl. Physiol., 5, 495.

24. GUYTON, A.C. (197.1): Fhysics of blood, blood flow, and pressure: Hemodynamics, Chapter 18 in Textbook of Medical Physiology, 4th ed., W.B. Saunders, Philadelphia, p. 204.

25. BRISTOW, J.D., HONOUR, A.J., PICKERING, G.W., SIEIGHT, P. and SMYTH, H.S. (1969): Diminished baroreflex sensitivity in high blood pressure, Circulatior 39,48 .

26. GRIBBIN, B., PICKERING, T.G., SLEIGHT, P. and PETRO, R. (1971) : Fffect of age and high blood pressure on baroreflex sensitivity in man, Circ. Res., 29,424.

27. KORNER, P.I., WEST, M.H., SHAW, J. and UTHER, J.B. (1974) : "Steady state" properties of the baroreceptor-heart reflex in essential hypertension in man, Clin. Exp. Pharmacol. Physiol., 1, 65. 


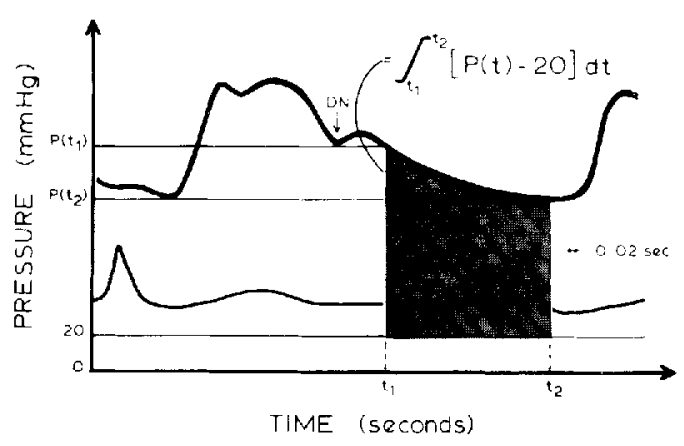

FIGURE 1. Pressure-pulse contour. The shaded area, calculated by the equation shown, is bounded on the pressure axis by a portion of the diastolic pressure-pulse contour above $\left(\mathrm{P}_{1}-\mathrm{P}_{2}\right)$ and by $20 \mathrm{~mm} \mathrm{Ha}$ below (see text). The lower limit of the time boundary, $t_{1}$, is $0.06-0.08$ sec after the peak of the dicrotic wave and the upper limit, $t_{2}$, is $0,20-0.24$ sec after $t_{1}$. DN $=$ dicrotic notch. Lead II of an electrocardiogram is shown below.

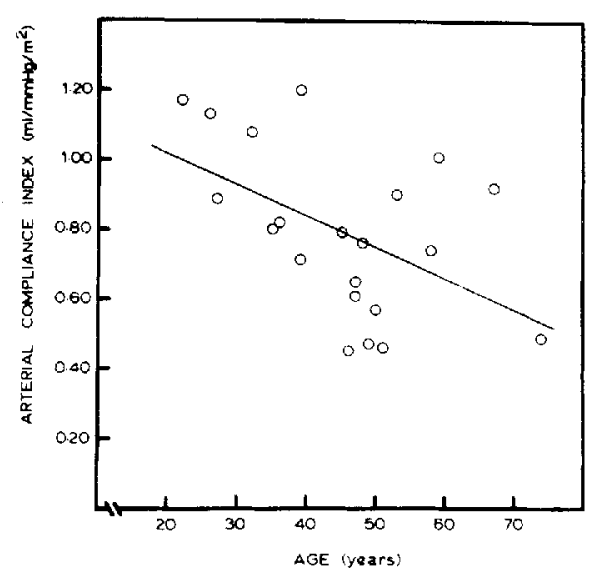

FIGURE 2. The correlation of age with systemic arterial compliance index (ACI) (determined from the ascending aorta) in 21 normotensive subjects; $r=-0.496$, p 0.05. The regression equation, $\mathrm{ACI}=$ $1.195-0.009$ (age), describes the linear relationship of age and ACI

\section{FIGURE 4.}

Systemic arterial compliance index as determined from the ascending aorta and brachial artery in relationship to the line of identity.

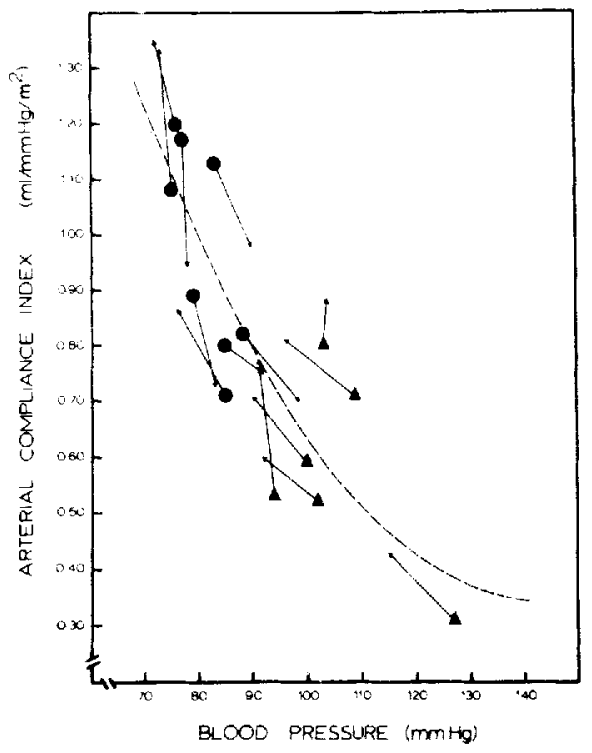

EIGURE 3. The relationship between mear arterial compliance index (ACI) and blood pressure (determined from the ascending aorta) in age-matched normotensive (closed circles) and hypertensive (closed triangles) subjects, is indicated by the curvilinear interrupted line. This quadratic equation is, $\mathrm{ACI}=4.0045-$ $5.3244 \times 10^{-2} \mathrm{BP}+1.9507 \times 10^{-4} \mathrm{BP}^{2}$ $\left(R^{2}=0.73, p 0.001\right)$. Arrows represent instantaneous variations in compliance, $\mathrm{dv} / \mathrm{dP}$, with blood pressure in each normotensive and hypertensive subject.

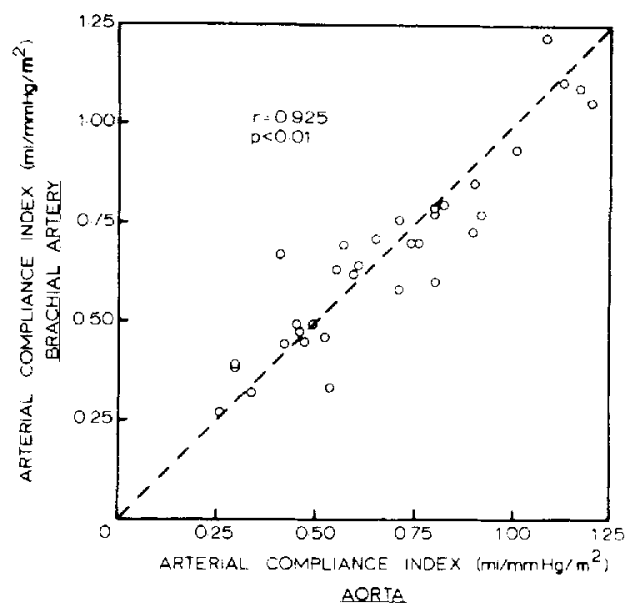




\section{DISCUSSION - CHALRMAN: PROFESSOR TAYIOR}

UR. O'ROURKE: There axe some uthex measurements of arterial complance which are well established, such as measuremerts of palsewave velocity. I wonder if you have had the opportunity to measuro pulse-wave velocity, to compare it with your index of compliance and to correlate it with some of these other factors that you have correlated with your own compliance mothod.

IJR. RANDALL: I think that's important. It has to be compared with some other standard method. We think this is more reliable than pulse-wave velocity. We have not done a large number of patients, but we have at the time of cardiac catheterisation, placed a catheter in the root of the aorta and pulled $j t$ back to got aistarce and then calculatcd pulse-wave velocity. There is a woak correlation in rine patients with a significance of just over 0.05 . We are at present continuing to about twenty-five or more patients to confinn thiss.

DR. WIKSTRAND: I wondor if you have atplied any correction for initial volume? you must have both volume ard wall stiffness here and with the Doppler method of o'Rourke for instance, it should be possible to apely a correction.

DR. RANDALL: Not to correct for the initial volume, I guess that's the difference in absolute and specific compliance; we are just looking at what happens to the pressure for a yiven change in volume for whatever volume is in that system. The only attempt to correct for initial volume we have used is body surface area to correct the differences in the total body sizo. But we have not done anything to look at $V_{O}$ in the calculation of compliance.

DR. GOW: The weak correlation you just showed between puise-wave velocily ard the parameter you're measuring is surprising considering that established studies have shown that the relationship between wave velocity and arterial elasticity and therefore compliance is rather good.

DR. RANDALL: Yes, that doesn't bother me much, in that the patients that we have studied so far ali were within a relatively narrow age $x$ ange and blocd pressuxe range. Wher we get patients of age say 20 to 80 years, or patients with wide ranges in blood pressure, I think we will see the correlation. But I am surprised that we almost have il just using patients between
40 and 55 years of age, where the pulse-wave velocity when you really look at those studies, was almost the same in all patients until you get ue to a fairly old age and in all of the studies they showed good correlation. There are 60,70 and 80 yoar old patients in there and I don't know whether they really had stiff vessels.

UR. HUNYOR: Can I ask whether frequency response of the pressure recording device, catheter delay etc. axe relevant for your type of medsurement and particularly did you take these factors into account when you were measuring the velocity charges that Dr. O'Rourke referred to?

DR. RANDALI: I would think that is important. We had a Bio-engineer who was one of the workers in this are. We used fluid filled catheters and we have plans now to use pressure tip transducers to look at this. I think it would make a difference. I don't think it would change the overal] Eindings of differences in groups of patients, hypertensive versus normotensive.

DR. BROD: Dr. Randall, I think it was a very nice presentation, but why was the last patient you showed us in the Intensive Care Unit with a blood pressure of 195/90nm and why did you treat him with nitroprusside?

DR. RANDALL: This patient was a 65 yoar old lady who presented to the coronary Care unit with acuto myocardial infarction, and we thought she had a phaeochromocytoma. Her diastolic pressure was going from 120 to around 220 ard at the time of admission she had a diastolic blood pressure of 150 . We could not control it other than with nitroprusside and we pit the catheters in.

DR. O'ROURKE: I am still pretty worried about this, because it is based on this assumption of a continuous fall of pressure in the aorta where you were measuring it. Under some circumstances you can have the pressure actual Iy rising during diastole to a second peak and even on the first slide in which you showed where you were taking the measurement, you are obviously part the way up a diastolio wave. I think in people with hypertension where you have an almost exponential fall-of and you don't have any oscillations in the arterial system, this type of thing is probably pretty reasonable, but under circumstances where there are 
prominent diastolic waves, I think it

becomes a littic bit worrying from a basic

theoretical point of viow.

DR. RANDAIL: I think that's important but I don't think it's always the caso; that first slide was the first one I made when I first studied this about two years ago. Now we always move a fair distance of $f$ the dicrotic wave. I think that if you use a small segment in the middle of the contour that you avoid most of the dicrotic wave. Even if you con't, I wonder. whether that increase in area is a reflection of what is going on with the pressure volume rolationship. That I don't know, but we have some studies now planned with the Bio-tngineers where we plan to $100 \mathrm{k}$ at some other events in diastole; where wo can get rid of the many changes in events in systole, such as ejection rates and $\mathrm{dp} / \mathrm{dt}$. 